\title{
$\infty$
}

\section{Optical Studies of a Pure and Dye Doped Nematic Liquid Crystal E-24}

\author{
V.S. CHANDEL ${ }^{+}$ \\ Department of Physics, Integral University, Lucknow-226026, U.P., India \\ S. MANOHAR \\ Department of Physics, R M L Awadh University, Faizabad, 224001, U.P., India \\ J. P. SHUKLA and R. MANOHAR \\ Department of Physics, University of Lucknow, Lucknow-226007, U. P., India
}

Received July 16, 2012; Revised July 31, 2012; Accepted July 31, 2012

The present paper reports the comparative optical behavior of a pure nematic mixture E-24 and its anthraquinone dye doped sample. The variation in the ordinary and extraordinary refractive index $\left(\mathrm{n}_{\mathrm{o}}, \mathrm{n}_{\mathrm{e}}\right)$ of the pure and dye doped samples with temperature has been discussed and it has been found that doped sample have a less refractive index compared to the pure sample. The variation in the order parameter for pure and doped samples with temperature has been discussed and it has been seen that the doped sample has a higher order parameter; the possible reasons have been discussed. The variations in birefringence and optical transmittance have also been presented here.

Keywords: Nematic liquid crystal, Dye, Refractive indices, Birefringence, Optical transmittance

\section{INTRODUCTION}

Liquid crystals are very important materials because of their technological importance, but a single liquid crystal material cannot fulfill all the requirements for a practical device. Therefore, the different mixtures of liquid crystals and their doped samples have gained growing interest. These doped samples have emerging prospects regarding their applications in information processing [1]. The doping can be done by dyes, polymers, composites, nano particles. Generally, dyes have an elongated molecular structure similar to the molecules of liquid crystals. When dyes are dissolved in the liquid crystals, they take up an orientation such that all the long axes lie substantially in

${ }^{\dagger}$ Author to whom all correspondence should be addressed:

E-mail: chandel.integral@gmail.com

Copyright @2012 KIEEME. All rights reserved.

This is an open-access article distributed under the terms of the Creative Commons Attribution Non-Commercial
License (http://creativecommons License (http://creativecommons.org/licenses/by-nc/3.0) which permits unrestricted
distribution, and reproduction in any medium, provided the original work is properly cited. the same direction as that of the molecules of liquid crystal. The magnitude for the ordering of the dye is very important, and if the dye molecule is long, it's ordering can be quite high in comparison to the ordering found in the liquid crystal. This occurs due to the reduction in thermal motion for the longer dye molecule. The long axis of the dye molecule does not absorb light very much while the axis orthogonal to the long molecular axis of the dye molecules absorbs more light than the shorter axis.

Liquid crystals also demonstrate a nonlinear response and are sensitive to their optical environments. Several nonlinear mechanisms have revealed the promising character of these materials. The difference in refractive indices measured along and perpendicular to the director axis brings a property birefringence $\left(\Delta \mathrm{n}=\mathrm{n}_{\mathrm{e}}-\mathrm{n}_{\mathrm{o}}\right)$ from the visible to the infrared region. This property provides an opportunity for various potential applications [2]. Director axis reorientation based effects causing a change of refractive index and observations of several interesting dynamic and storage wave-mixing effects have also been extensively studied [2-4].

It has been found that doping with a small amount of dye de- 


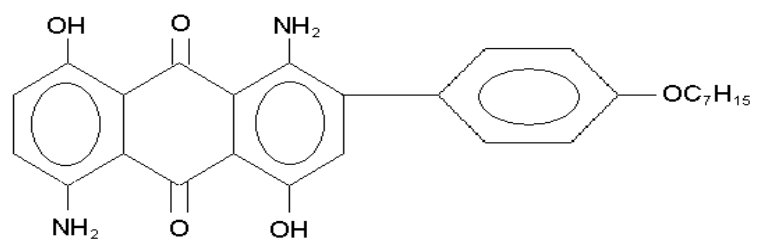

Fig. 1. Anthraquinone dye used for present investigation.

creases the required threshold of molecular reorientation in dyedoped nematic liquid crystals. This phenomenon demonstrates potential application in areas such as holographic data storage. Birefringence property and its dependency on molecular reorientation play an important role in understanding the molecular mechanism. Moreover, birefringence enhancement is of primary importance for the innovation of different electro-optic applications [5,6]. Various studies have been done to study the effects of dye, $\mathrm{C}_{60}$, polymer, carbon nanotube (CNT) and their combinations on liquid crystal properties [7-16]. Our group has also reported the effect of dye and nano particles on the dielectric and optical properties of nematic liquid crystals [14-17]. The refractive indices, order parameter, density and optical transmittance for pure nematic mixture E-24 have already been published by our group [18].

In view of the above requirements, it is worthwhile to study the properties of a dye doped liquid crystal.

\section{EXPERIMENTS}

The sample used for the present investigation was nematic mixture E-24 supplied by BDH, England, and it was used without further purification. The transition scheme of the sample is as follows

$$
\text { Crystal } \stackrel{-5^{\circ} \mathrm{C}}{\longrightarrow} \text { Nematic } \stackrel{54^{\circ} \mathrm{C}}{\longrightarrow} \text { Isotropic }
$$

The dye used for preparing the guest-host mixture is an anthraquinone dye, 1,5-Diamino-2(4-heptyloxy-phenyl)-4,8- dihydroxy-anthraquinone, (Chemical Composition: $\mathrm{C}_{27} \mathrm{H}_{23} \mathrm{~N}_{2} \mathrm{O}_{5}$ ). The structure of the dye is given in Fig. 1. The method of preparation regarding the guest-host mixture has been discussed in our earlier paper [17]. The ordinary refractive index $\left(n_{0}\right)$ has been measured using Abbe's refractometer within an accuracy of 0.0001 . The wedge method $[19,20]$ was used for the determination of the extraordinary refractive index $\left(\mathrm{n}_{\mathrm{e}}\right)$ for the material, which was modified by Sarna et al. [21,22], as the extraordinary refractive index is sometimes greater than the measuring limit of Abbe's refractometer. The guest-host mixture with anthraquinone dye was used for measuring the ordinary and extraordinary refractive indices of the dye doped sample.

The nematic-isotropic transition temperature of the nematic sample E-24 and that of the dye doped sample have also been identified with the help of optical transmittance. The process of optical transmittance measurement has already been discussed elsewhere [17].

\subsection{Theory}

Since a homogeneously aligned nematic sample behaves like a uniaxial crystal, the relation between the refractive indices parallel and perpendicular to the director of the molecular alignment

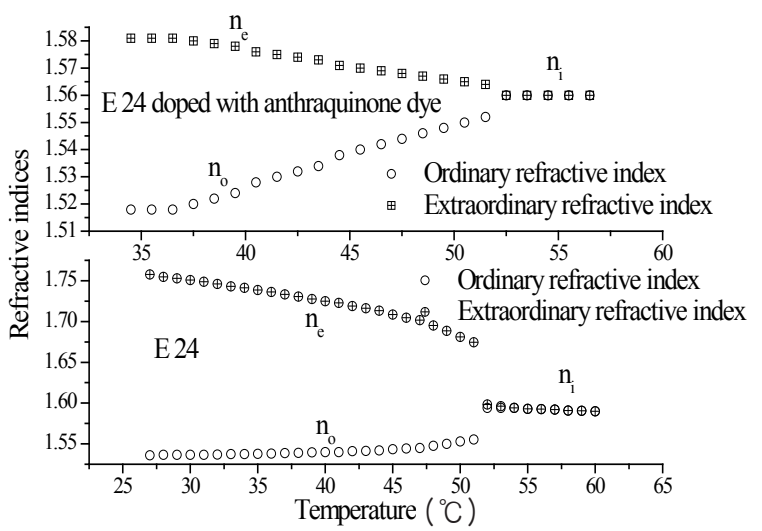

Fig. 2. Plot between refractive indices and temperature for the pure and dye doped sample (E-24 and its guest-host mixture with anthraquinone dye).

and macroscopic order parameter (Q) may be given as:

$$
\begin{aligned}
& n_{\|}=\bar{n}+\frac{2}{3} Q \cdot \Delta n \\
& n_{\perp}=\bar{n}-\frac{1}{3} Q \cdot \Delta n
\end{aligned}
$$

Here, $\bar{n}$ is the average refractive index and $\Delta \mathrm{n}$ is the birefringence corresponding to complete the alignment and for uniaxial crystal $n_{\|}=n_{e}, n_{\perp}=n_{o}[23]$. From the above Eqs. 1 and 2, we obtain

$$
Q=\frac{n_{\|}-n_{\perp}}{\Delta n}=\frac{n_{e}-n_{o}}{\Lambda n}=\frac{\delta n}{\Delta n}
$$

where $\delta \mathrm{n}=\mathrm{n}_{\mathrm{e}}-\mathrm{n}_{\mathrm{o}}$

The value of macroscopic order parameter $Q=1$ shows the complete order of the sample at absolute zero temperature, that is at $0 K, \delta n=\Delta n$. Thus, the macroscopic order parameter $Q$ has been obtained by extrapolating $\delta \mathrm{n}$ for $\mathrm{T}=0 \mathrm{~K}$. This extrapolation is done on the linear portion of the graph drawn between the birefringence $(\delta \mathrm{n})$ versus $\ln (1-\mathrm{T} / \mathrm{Tc})$ as reported by others [21, 24].

\section{RESULTS AND DISCUSSION}

The variation of ordinary and extraordinary refractive indices $\left(\mathrm{n}_{\mathrm{o}}, \mathrm{n}_{\mathrm{e}}\right)$ with temperature for the nematic sample E-24 along with the guest-host mixture (with anthraquinone dye) is shown in Fig. 2. In the isotropic phase, both samples show similar behaviour in that the refractive index decreases with an increase in temperature like other normal liquid crystals [24]. The ordinary and extraordinary refractive indices $\left(\mathrm{n}_{0}, \mathrm{n}_{\mathrm{e}}\right)$ of the guest-host mixture are slightly less than that of the nematic sample E-24 [25-27]. The nematic-isotropic transition temperature of the sample E-24 is $54^{\circ} \mathrm{C}$ while that of the guest-host mixture is $51^{\circ} \mathrm{C}$, and at these temperatures the values of refractive indices change abruptly. A similar type of behaviour has also been reported for other nematic mixtures by several other workers [17, 25-27].The change in transition temperature of the guest-host mixture is approximately $3{ }^{\circ} \mathrm{C}$, and such a small change in transition temperature 


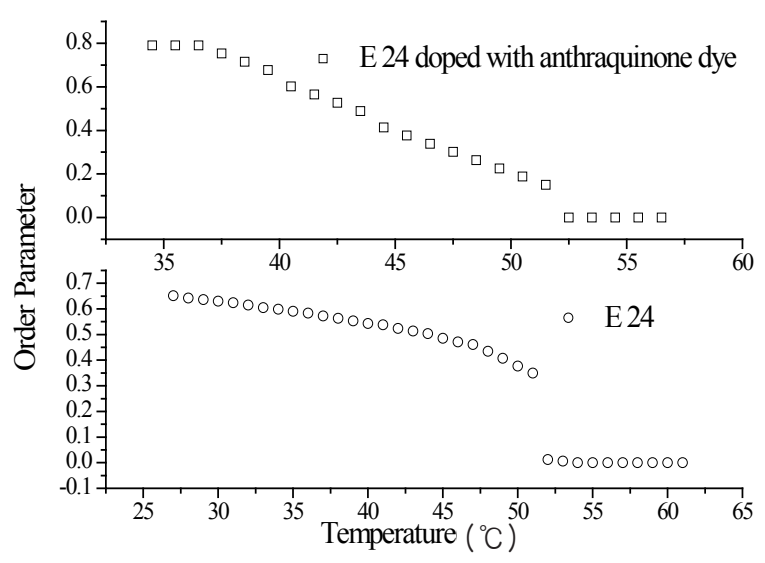

Fig. 3. Plot between order parameter and temperature for the pure and dye doped sample (E-24 and its guest-host mixture with anthraquinone dye).

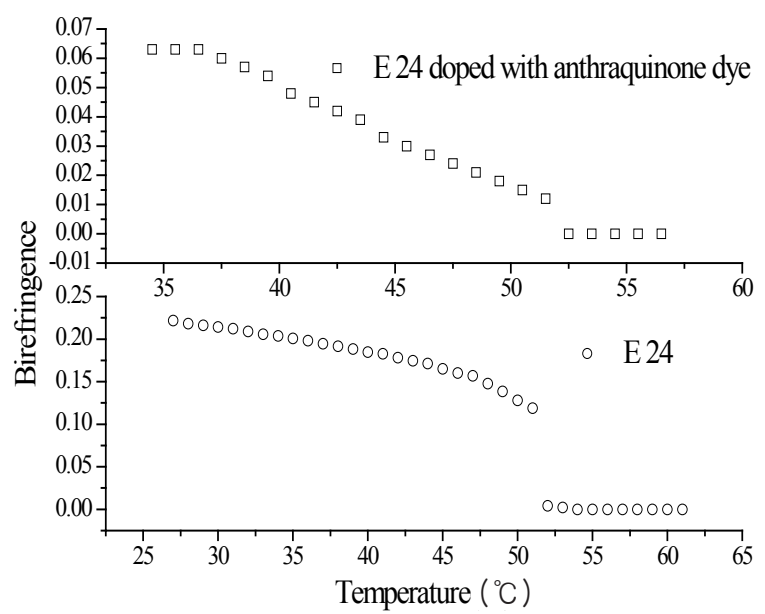

Fig. 4. Plot between optical birefringence and temperature for the pure and dye doped sample (E-24 and its guest-host mixture with anthraquinone dye)

was expected possibly because of the presence of the dye molecules in the nematic host, as they act as an impurity to the host. W. Haase et al. reported similar behaviour in a nematic host [28]. It is worth mentioning here that the clearing point can either increase or decrease depending on the compatibility of the dye with the host $[26,28,29]$.

Figure 3 shows the variation of the macroscopic order parameter (Q) for nematic E-24 along with the guest-host mixture. It may be seen that the order parameters of both samples change abruptly at the nematic-isotropic transition, that is, at $54^{\circ} \mathrm{C}$ and $51^{\circ} \mathrm{C}$ for the nematic E-24 and guest-host mixture, respectively. The macroscopic order parameter of the guest-host mixture is slightly greater than that of the nematic E-24. This type of behaviour has also been reported by several researchers [28,30,31], but Chigrinov et al. revealed that there is a large decrease in the order parameter [32].

The variation of birefringence $(\delta \mathrm{n})$ with temperature (Fig. 4) shows that $\delta \mathrm{n}$ becomes zero at temperatures $54^{\circ} \mathrm{C}$ and $51^{\circ} \mathrm{C}$ for the nematic E-24 and guest-host mixture, respectively, indicating the isotropic phase of the samples. In the nematic region, the birefringence decreases with an increase in temperature. The birefringence of the guest-host mixture also decreases as in the case of the host E-24 and has been previously reported [25]. This

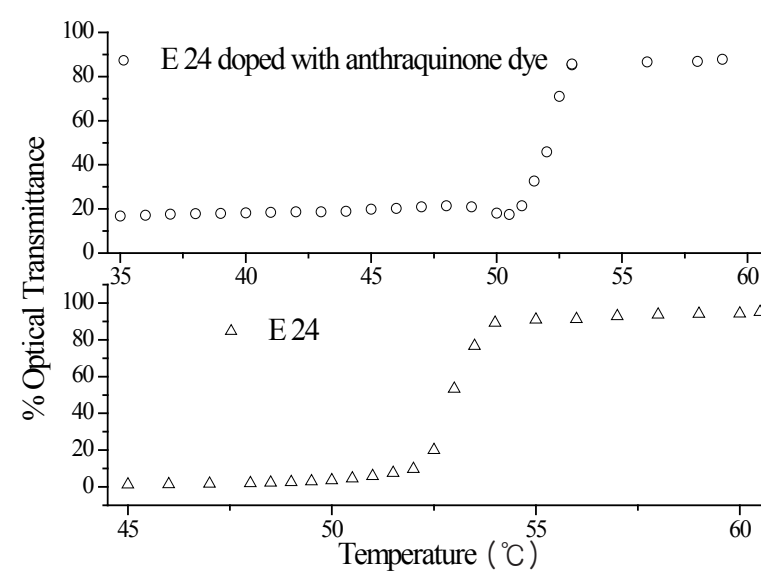

Fig. 5. Variation of percentage optical impedance with temperature for the pure and dye doped sample (E-24 and its guest-host mixture with anthraquinone dye).

may increase or decrease depending upon the compatibility of the dye with the host material.

Fig. 5 presents the variation of percentage optical transmittance with temperature for the nematic sample E-24 along with its guest-host mixture. The optical transmittance of the nematic E-24 as well as of the guest-host sample first increases slowly with an increase in temperature, and then it shows an abrupt increase at the nematic-isotropic transition for both samples. And as the samples go into the isotropic phase, the optical transmittance attains its maximum value. With further increase in temperature it remains almost constant. This type of behaviour has been reported by others researchers including our group [1617]. It can be seen that the optical transmittance of the guesthost mixture is greater than that of the nematic E-24, possibly because the dyes absorb more light along one axis compared to the others [33].

The phase-transition temperatures of the nematic E-24 and guest-host mixtures obtained from the polarizing microscope are not sharp. The breadth of the nematic-isotropic transition was also observed by Singh et al. [22], who concluded that the sharpness of the transition temperature depends on the purity (single component) of the sample. The sample used in the present investigation is a nematic-mixture and the constituents may behave like an impurity towards each other while in the case of the guest-host mixture, the dye molecules are behaving like an impurity for the host material.

\section{CONCLUSIONS}

It may be concluded that the phase transitions obtained by different techniques are in good agreement for the nematic mixture E-24 and also for the guest-host mixture. A slightly broader breadth of the phase transition by the optical transmittance measurement may be due to the presence of different components in the nematic mixture E-24, while in the guest-host mixture it may be due to the dye molecule. As expected, the optical transmittance of the guest-host mixture yields a greater value. Furthermore, the macroscopic order parameter of the guest-host mixture also increases.

\section{REFERENCES}

[1] M. Zennyoyi, J. Yokoyama, Y. Takanishi, K. Ishikawa, H. Take- 
zone and K. Itoh, Jap. J. Appl. Phys. 37(11), 6071 (1998) [DOI http://dx.doi.org/10.1143/JJAP.37.6071].

[2] L. M. Blinov and V. G. Chigrinov, Electrooptic Effects in Liquid Crystal Materials, Springler-Verlag, New York (1996).

[3] I. C. Khoo, M. Shih, M. V. Wood, B. D. Guenther, P. H. Chen, F. Simoni, S. S. Slussarenko, O. Francescangeli and L. Lucchetti, Procedings of the IEEE. 87(11), 1897 (1999) [DOI: http://dx.doi org/10.1109/5.796353].

[4] S. Bartkiewicz, A. Januszko, A. Miniewicz and J. Parka, Pure Appl. Opt. 5, 799 (1996) [DOI: http://dx.doi.org/ doi:10.1088/0963-9659/5/6/006].

[5] S. E. San, O. Koysal and F. N. Ecevit, Opt. Commun. 212, 405 (2002) [DOI: http://dx.doi.org/10.1016/S0030-4018 (02)02018-7].

[6] S. T. Wu, Phys. Rev. A. 33(2), 1270 (1986) [DOI: http://dx.doi org/10.1103/PhysRevA.33.1270].

[7] S. Ghosh and G.O. Carlisle, J. Mat. Sci. Mat. Elect. 16, 753 (2005) [DOI: http://dx.doi.org/10.1007/s10854-005-4979-0].

[8] Y. S. Suleiman, S. Ghosh, M. E. Abbasov and G. O. Carlisle, J. Mat.Sci. Mat. Elect. 19(7), 662 (2008) [DOI: http://dx.doi org/10.1007/s10854-007-9416-0].

[9] I. Dierking, G. Scalia and P. Morales, J. Appl. Phys. 97(4), 044309 (2005) [DOI: http://dx.doi.org/10.1063/1.1850606].

[10] W. Lee, C.Y. Wang and Y.C. Shih, Appl. Phys. Lett. 85, 513 (2004) [DOI: http://dx.doi.org/10.1063/1.1771799].

[11] S. E. San, O. Koysal, F. N. Ecevit, S. Ozder and D. Dvornikov, Sythn. Met. 142, 283 (2004) [DOI: http://dx.doi.org/10.1016/ j.synthmet.2003.10.008]

[12] O. Koysal and S. E. San, Sythn. Met. 158, 527 (2008) [DOI: http://dx.doi.org/10.1016/j.synthmet.2008.03.017].

[13] M. E. Abbasov, and G.O. Carlisle, J. Nanophoton. 2, 023510 (2008) [DOI: http://dx.doi.org/10.1117/1.3037329].

[14] R. Manohar, S. P. Yadav, A. K. Srivastava, A. K. Misra, K. K. Pandey, P. K. Sharma and A. C. Pandey, Jap. J. of Appl. Phys. 48 101501 (2009) [DOI: http://dx.doi.org/10.1143/JJAP.48.101501].

[15] S. P. Yadav, K. K. Pandey, A. K. Misra and R. Manohar, Acta Physica Polonica A, 119(6), 824 (2011).

[16] D. Pal, P. Mishra, A. K. Mishra, R. Manohar and J. P. Shukla, Res. J. Phys. 1(1), 10 ( 2007).

[17] R. Manohar, S. Manohar and V. S. Chandel, Materials Sciences and Appl. 2, 839 (2011) [DOI: http://dx.doi.org/10.4236/ msa.2011.27114]

[18] A. K. Singh, R. Manohar, J. P. Shukla and A. M. Biradar, Acta Physica Polonica A, 110(4), 485 (2006).

[19] E. G. Hanson and Y. R. Shen, Mol. Cryst. Liq. Cryst. 36(3-4), 193 (1976) [DOI: http://dx.doi.org/10.1080/15421407608084323].

[20] I. Haller, H. A. Huggins and M. J. Freiser, Mol. Cryst. Liq. Cryst. 16, 53 (1972) [DOI: http://dx.doi. org/10.1080/15421407208083579].

[21] R. K. Sarna, B. Bahadur and V. G. Bhide, Mol. Cryst. Liq. Cryst. 51(1-2), 117 (1979) [DOI: http://dx.doi. org/10.1080/00268947908084697].

[22] R. Singh, V. K. Agrawal, P. P. Anand and V. P. Arora, Nat. Acad. Sci. Lett. India. 13, 129 (1990).

[23] W. H. De Jeu, Physical Properties of Liquid Crystalline Materials, Gorden and Breach Scientific Publisher, New York, (1980).

[24] V. S. Chandel, R. Manohar and J. P. Shukla, Analele UniversităŃii din Bucuresti - Chimie (serie nouă) 20(02), 155 (2011).

[25] D. Bauman, Mol. Cryst. Liq. Cryst. 159, 197 (1988) [DOI: http:// dx.doi.org/10.1080/00268948808075272.

[26] D. Bauman, Mol. Cryst. Liq. Cryst. 172, 41 (1989) [DOI: http:// dx.doi.org/10.1080/00268948908042149].

[27] S. T. Wu, C. S. Hsu and K. F. Shyu, Appl. Phys. Lett. 74, 344 (1998) [DOI: http://dx.doi.org/10.1063/1.123066].

[28] W. Haase, O. Trinquet, U. Quotschalla and J. K. Foitzik, Mol. Cryst. Liq. Cryst. 148(1), 15 (1987) [DOI: http://dx.doi. org/10.1080/00268948708071776].

[29] M. Kozielski, D. Bauman, M. Drozdowski and Z. Salamon, Mol. Cryst. Liq. Cryst. 142, 1 (1987) [DOI: http://dx.doi. org/10.1080/00268948708084589].

[30] A. Shishido, M. Y. Shih and I. C. Khoo, J. Nonlinear Optical Phys. and Mats. 11(1), 1(2002) [DOI: http://dx.doi.org/10.1142/ S0218863502000900].

[31] S. Imazeki, A. Mukoh, T. Yoneyama and M. Kaneko, Mol. Cryst. Liq. Cryst. 145, 79 (1987) [DOI: http://dx.doi. org/10.1080/00268948708080215].

[32] V. Chigrinov, E. Prudnikova, K.W. Ng A. Drushlyak and H. S. Kwok, Jap.J Appl. Phys. 43(3), 1100 (2004) [DOI: http://dx.doi. org/10.1143/JJAP.43.1100].

[33] D. L. White and G. N. Taylor, J. Appl. Phys. 45, 4718 (1974) [DOI: http://dx.doi.org/10.1063/1.1663124]. 